\title{
Two New Clerodane-type Diterpenoids from Gomphostemma microdon
}

\author{
Rong-Ting Zhang ${ }^{\mathrm{a}, \mathrm{b}}$, Tao Feng ${ }^{\mathrm{a}, \mathrm{b}}$, Xiang-Hai Cai ${ }^{\mathrm{a}}$, and Xiao-Dong Luo ${ }^{\mathrm{a}}$ \\ ${ }^{a}$ State Key Laboratory of Phytochemistry and Plant Resources in West China, Kunming Institute of \\ Botany, Chinese Academy of Sciences, 132 Lanhei Road, Kunming 650204, P. R. China \\ $\mathrm{b}$ Graduate School of Chinese Academy of Sciences, Beijing 100039, P. R. China
}

Reprint requests to Prof. Dr. Xiao-Dong Luo. Fax: +86-871-5150227. E-mail: xdluo@mail.kib.ac.cn

Z. Naturforsch. 2009, 64b, 443 -446; received November 30, 2008

Two new clerodane-type diterpenoids, along with seven known compounds have been isolated from the aerial parts of Gomphostemma microdon. All structures were established on the basis of spectroscopic analyses, including application of MS, UV, IR, 1D and 2D NMR techniques.

Key words: Gomphostemma microdon, Clerodane Diterpenoids, Microdon A, Microdon B Diterpenes

\section{Introduction}

The genus Gomphostemma is a member of the Labiatae family and comprises about forty species, which are distributed throughout tropical and subtropical areas. Sixteen species are found in China. Gomphostemma microdon, a herb plant, is widely distributed in the south and southwest of China, which has been used as a menoxenia drug as well as for the treatment of cough and for eliminating phlegm by the local people $[1,2]$. Various medicinal uses of the genus Gomphostemma have been reported in Yunnan Province of China. However, phytochemical research on the genus showed only a few types of sterols and terpenoids [3]. Moreover, the absence of chemical reports on $\mathrm{G}$. $\mathrm{mi}$ crodon further prompted us to study it.

In this paper, we report the isolation and structure elucidation of two new clerodane-type diterpenoids, named microdon A (1) and B (2) (Fig. 1), together with seven known compounds, phytol (3) [4], betulinic acid (4) [5], 3-taraxeranol (5) [6], 4',5-dihydroxy-7methoxyflavone (6) [7], 5-hydroxy-2-methoxybenzoic acid (7) [8], 3-hydroxystigmast-7-en-11-one (8) [9] and apigenin (9) [10] from the methanol extract of aerial parts of the title plant.

\section{Results and Discussion}

Compound 1 has a molecular formula $\mathrm{C}_{20} \mathrm{H}_{25} \mathrm{O}_{4}$ derived from HRMS $((+)$-ESI) at $\mathrm{m} / z=329.1774$ (calcd. 329.1752 for $\left.\mathrm{C}_{20} \mathrm{H}_{25} \mathrm{O}_{4}\right)$ in combination with ${ }^{1} \mathrm{H}$ and ${ }^{13} \mathrm{C}$ NMR data (Table 1 ). The IR spectrum of $\mathbf{1}$ re-

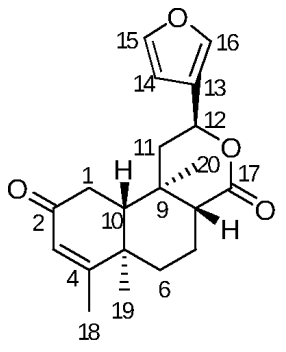

1

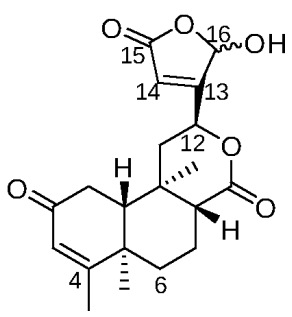

2
Fig. 1. Chemical structures of $\mathbf{1}$ and $\mathbf{2}$.

vealed the presence of a furan ring (1504, 1022, 872 and $817 \mathrm{~cm}^{-1}$ ) [11] and of $\alpha, \beta$-unsaturated ketone group functionalities $\left(1652 \mathrm{~cm}^{-1}\right)$ which were supported by ${ }^{1} \mathrm{H}$ NMR signals at $\delta_{\mathrm{H}}=7.40(1 \mathrm{H}, \mathrm{s}), 7.38$ $(1 \mathrm{H}, \mathrm{d}, J=1.4 \mathrm{~Hz})$, and $6.37(1 \mathrm{H}, \mathrm{d}, J=1.4 \mathrm{~Hz})$ and the UV absorption band at $243 \mathrm{~nm}$ [12], respectively. The ${ }^{1} \mathrm{H}$ NMR spectrum showed 3 tertiary methyls at $\delta_{\mathrm{H}}=1.13,1.17$, and 1.89. Additionally, the ${ }^{13} \mathrm{C} \mathrm{NMR}$ spectrum showed 20 carbon signals, 5 quaternary carbons $\left(\delta_{\mathrm{C}}=198.2,171.3,170.9,38.7,36.3\right), 7$ methines $\left(\delta_{\mathrm{C}}=143.5,139.0,125.3,108.1,71.5,50.9,50.2\right), 3$ methylenes $\left(\delta_{\mathrm{C}}=42.8,34.2,17.8\right)$, and 3 methyls $\left(\delta_{\mathrm{C}}=\right.$ $18.4,18.1,14.1)$. The above NMR data have shown that 1 has the clerodane diterpenoid skeleton. Comparison of the ${ }^{13} \mathrm{C}$ and ${ }^{1} \mathrm{H}$ NMR spectra with those of tinophyllone [13] suggested that both planar structures were similar except that the methyl ester group changed to methyl. This proposal was supported by the HMBC correlations between $\delta_{\mathrm{H}}=1.89(3 \mathrm{H}, \mathrm{s})$ with $\delta_{\mathrm{C}}=125.3(\mathrm{C}-3, \mathrm{~d}), 170.9(\mathrm{C}-4, \mathrm{~s}), 198.2(\mathrm{C}-2, \mathrm{~s})$ and 


\begin{tabular}{lllll}
\hline No. & \multicolumn{1}{c}{$\mathbf{1}$} & & \multicolumn{2}{l}{$\mathbf{2}$} \\
& $\delta_{\mathrm{H}}$ & $\delta_{\mathrm{C}}$ & $\delta_{\mathrm{H}}$ & $\delta_{\mathrm{C}}$ \\
\hline 1 & $2.39(2 \mathrm{H}, \mathrm{dd})$ & $34.2(\mathrm{t})$ & $2.63(2 \mathrm{H}, \mathrm{dd})$ & $34.4(\mathrm{t})$ \\
2 & - & $198.2(\mathrm{~s})$ & - & $199.2(\mathrm{~s})$ \\
3 & $5.71(1 \mathrm{H}, \mathrm{s})$ & $125.3(\mathrm{~d})$ & $5.74(1 \mathrm{H}, \mathrm{s})$ & $125.7(\mathrm{~d})$ \\
4 & - & $170.9(\mathrm{~s})$ & - & $171.0(\mathrm{~s})$ \\
5 & - & $38.7(\mathrm{~s})$ & - & $36.8(\mathrm{~s})$ \\
6 & $1.39(1 \mathrm{H}, \mathrm{m})$ & $34.2(\mathrm{t})$ & $1.41(1 \mathrm{H}, \mathrm{m})$ & $34.6(\mathrm{t})$ \\
& $1.98(1 \mathrm{H}, \mathrm{m})$ & & $2.00(1 \mathrm{H}, \mathrm{m})$ & \\
7 & $1.69(1 \mathrm{H}, \mathrm{m})$ & $17.8(\mathrm{t})$ & $1.68(1 \mathrm{H}, \mathrm{m})$ & $18.3(\mathrm{t})$ \\
& $2.15(1 \mathrm{H}, \mathrm{overlap})$ & & $2.15(1 \mathrm{H}, \mathrm{overlap})$ & \\
8 & $2.16(1 \mathrm{H}, \mathrm{overlap})$ & $50.2(\mathrm{~d})$ & $2.16(1 \mathrm{H}, \mathrm{overlap})$ & $50.6(\mathrm{~d})$ \\
9 & - & $36.3(\mathrm{~s})$ & - & \\
10 & $1.83(1 \mathrm{H}, \mathrm{t}, J=9.0)$ & $50.9(\mathrm{~d})$ & $1.87(1 \mathrm{H}, \mathrm{m})$ & $51.2(\mathrm{~d})$ \\
11 & $2.24(1 \mathrm{H}, \mathrm{dd}, J=13.5,5.5 \mathrm{~Hz})$ & $42.8(\mathrm{t})$ & $1.65(1 \mathrm{H}, \mathrm{overlap})$ & $40.9(\mathrm{t})$ \\
& $1.65(1 \mathrm{H}, \mathrm{d}, J=13.5 \mathrm{~Hz})$ & & $2.24(1 \mathrm{H}, \mathrm{overlap})$ & \\
12 & $5.50(1 \mathrm{H}, \mathrm{dd}, J=11.2,5.7 \mathrm{~Hz})$ & $71.5(\mathrm{~d})$ & $5.46(1 \mathrm{H}, \mathrm{m})$ & $72.8(\mathrm{~d})$ \\
13 & - & $125.2(\mathrm{~s})$ & - & $166.0(\mathrm{~s})$ \\
14 & $6.37(1 \mathrm{H}, \mathrm{d}, J=1.4 \mathrm{~Hz})$ & $108.1(\mathrm{~d})$ & $6.22(1 \mathrm{H}, \mathrm{br} \mathrm{s})$ & $117.7(\mathrm{~d})$ \\
15 & $7.38(1 \mathrm{H}, \mathrm{d}, J=1.4 \mathrm{~Hz})$ & $143.5(\mathrm{~d})$ & - & $169.8(\mathrm{~s})$ \\
16 & $7.40(1 \mathrm{H}, \mathrm{s})$ & $139.0(\mathrm{~d})$ & $6.09(1 \mathrm{H}, \mathrm{br} \mathrm{s})$ & $97.5(\mathrm{~d})$ \\
17 & - & $171.3(\mathrm{~s})$ & - & $172.2(\mathrm{~s})$ \\
18 & $1.89(3 \mathrm{H}, \mathrm{s})$ & $14.1(\mathrm{q})$ & $1.93(3 \mathrm{H}, \mathrm{s})$ & $14.3(\mathrm{q})$ \\
19 & $1.17(3 \mathrm{H}, \mathrm{s})$ & $18.1(\mathrm{q})$ & $1.18(3 \mathrm{H}, \mathrm{s})$ & $18.5(\mathrm{q})$ \\
20 & $1.13(3 \mathrm{H}, \mathrm{s})$ & $18.4(\mathrm{q})$ & $1.14(3 \mathrm{H}, \mathrm{s})$ & $18.7(\mathrm{q})$ \\
\hline & & & &
\end{tabular}

Table 1. NMR data of $\mathbf{1}$ and 2 in $\mathrm{CDCl}_{3}$ solution $(500 \mathrm{MHz}$ for ${ }^{1} \mathrm{H}$ and $100 \mathrm{MHz}$ for ${ }^{13} \mathrm{C}, \delta$ in ppm, $J$ in $\mathrm{Hz}$ ). Assignments are based on DEPT, HSQC and HMBC spectra.

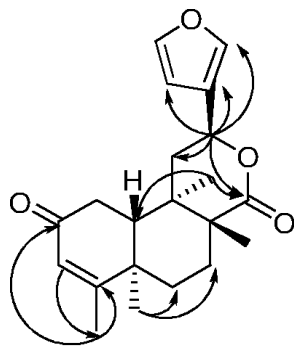

1

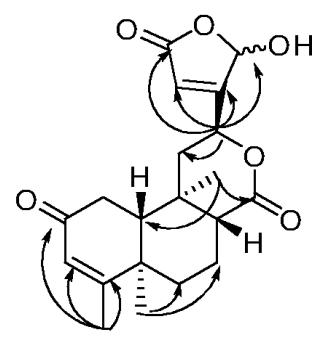

2
Fig. 2. Key HMBC correlations of $\mathbf{1}$ and $\mathbf{2}$.

18.1 (C-19, s) (Fig. 2). On the basis of HMBC, HSQC experiments, all carbons and protons were unambiguously assigned. Thus, we named it as microdon A.

The relative configuration of $\mathbf{1}$ was deduced by a ROESY experiment. Crosspeaks from $\mathrm{H}-1\left(\delta_{\mathrm{H}}=2.39\right.$, $2 \mathrm{H}$, dd) to $\mathrm{H}-19$ and $\mathrm{H}-20$, and from $\mathrm{H}-12$ to $\mathrm{H}-20$ indicated that these atoms are at the same side in $\alpha$-orientation. ROESY correlations of $\mathrm{H}-10 / \mathrm{H}-8$ and the absent correlation of $\mathrm{H}-19 / \mathrm{H}-10$ suggested that $\mathrm{H}-10$ and $\mathrm{H}-8$ are $\beta$-oriented $[13,14]$. Thus, the relative configuration of microdon $\mathrm{A}$ is as represented in Fig. 3.

Compound 2 showed in its HRMS ((+)-ESI) spectrum a molecular ion peak at $m / z=361.1666[\mathrm{M}+\mathrm{H}]^{+}$ in accordance with the formula $\mathrm{C}_{20} \mathrm{H}_{24} \mathrm{O}_{6}$. The IR spectra of $\mathbf{2}$ indicated the presence of a hydroxyl

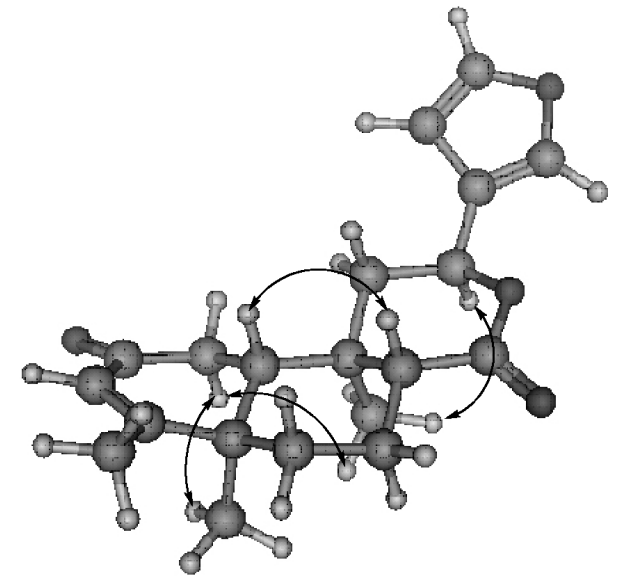

Fig. 3. Key ROESY correlations of $\mathbf{1}$.

group $\left(3323 \mathrm{~cm}^{-1}\right)$ and of $\alpha, \beta$-unsaturated carbonyl $\left(1653 \mathrm{~cm}^{-1}\right)$ functionalities. Careful analysis of the ${ }^{13} \mathrm{C}$ and ${ }^{1} \mathrm{H}$ NMR spectra of $\mathbf{2}$ implied that this compound might be an analog of $\mathbf{1}$. However, they differ in the chemical shifts of the $\beta$-furan ring. The ${ }^{13} \mathrm{C}$ NMR signals $\left[\delta_{\mathrm{C}}=169.8(\mathrm{~s}), 166.0(\mathrm{~s}), 117.7(\mathrm{~d})\right]$ suggested the existence of another $\alpha, \beta$-unsaturated carbonyl which was supported by the HMBC correlation between $\mathrm{H}-12$ at $\delta_{\mathrm{H}}=5.46(1 \mathrm{H}, \mathrm{m})$ with $\delta_{\mathrm{C}}=117.7(\mathrm{~d})$, $166.0(\mathrm{~s})$, and 169.8 (s). In addition, the acetal group $\left[\delta_{\mathrm{C}}=97.5(\mathrm{~d})\right]$ also showed correlation with H-12. So a $\gamma$-hydroxy- $\alpha, \beta$-unsaturated $\gamma$-lactone was indicated. 


\section{Experimental Section}

\section{General}

Optical rotations were measured with a Horiba SPEA300 spectropolarimeter. All melting points were measured on an XRC-1 apparatus and are uncorrected. One- and twodimensional NMR experiments were performed on Bruker AM-400 MHz and DRX-500 MHz NMR spectrometers with tetramethylsilane as the internal standard. MS ((+)-ESI) and HRMS ((+)-ESI) spectral data were obtained on a API Qstar Palsar I mass spectrometer. IR spectra were measured on a Brucker Tensor 27 spectrometer with $\mathrm{KBr}$ pellets. UV spectra were taken on a Shimadzu 2401PC spectrophotometer. RP-18 silica gel $(40-65 \mu \mathrm{m})$ was bought from Merck, Germany. Silica gel (200 - 300 mesh) for column chromatography and $\mathrm{GF}_{254}$ for TLC were obtained from the Qindao Marine Chemical factory, Qindao, P. R. China. Compounds were detected under UV (254 $\mathrm{nm}$ and $365 \mathrm{~nm}$ ) before spraying with an anisaldehyde sulfuric acid solution followed by heating.

\section{Plant material}

The aerial parts of Gomphostemma microdon were collected from Xishuangbanna, Yunnan Province, People's Republic of China, in April 2007. Its identity was confirmed by Mr. Jing-yun Cui, and a voucher specimen (NO. 200704) has been deposited in the State Key Laboratory of Phytochemistry and Plant Resources in West China, Kunming Institute of Botany, Chinese Academy of Sciences.

\section{Extraction and isolation}

The dried and milled sample $(10 \mathrm{~kg})$ was soaked in $95 \%$ $\mathrm{MeOH}(40 \mathrm{~L} \times 3)$ under reflux $(48 \mathrm{~h} \times 3)$, and the solvent was evaporated. The residue was partitioned between EtOAc and $\mathrm{H}_{2} \mathrm{O}$ to give an EtOAc-soluble fraction. This fraction $(150 \mathrm{~g})$ was chromatographed on a prepacked silica gel $(2.0 \mathrm{~kg}, 200-300 \mathrm{mesh})$ column, using a mixture of $\mathrm{CHCl}_{3}-\mathrm{Me}_{2} \mathrm{CO}$ [from $\mathrm{CHCl}_{3}-\mathrm{Me}_{2} \mathrm{CO}(10: 1)$ to $\mathrm{CHCl}_{3}$ $\left.\mathrm{Me}_{2} \mathrm{CO}(1: 1)\right]$, to give eight fractions (I-VIII). Fraction II $(10.3 \mathrm{~g})$ was submitted to silica gel $(200 \mathrm{~g})$ and eluted with petroleum ether- $\mathrm{CHCl}_{3}(8: 1,4: 1,1: 1)$, to yield subfraction A. Subfraction A was purified by silica gel and eluted with petroleum ether- $\mathrm{Me}_{2} \mathrm{CO}$ to afford compound 3 $(938.5 \mathrm{mg})$. Fraction III $(12.0 \mathrm{~g})$ was submitted to silica gel $(300 \mathrm{~g})$ and eluted with petroleum ether-Me $\mathrm{MeO}_{2} \mathrm{C}(12: 1$, $10: 1,8: 1,4: 1$ ), to yield subfractions B-D. Subfraction B was purified on Sephadex LH-20 $\left(\mathrm{CHCl}_{3}: \mathrm{MeOH}=1: 1\right)$, to yield compound $4(618.7 \mathrm{mg})$. Subfraction $C$ was purified by silica gel and eluted with petroleum ether-EtOAc to afford compound 5 (38.5 mg). Subfraction D was applied on RP18 using $\mathrm{MeOH}-\mathrm{H}_{2} \mathrm{O}$, to give compounds $6(51.3 \mathrm{mg})$ and 7 (33.6 mg). Fraction IV (19.0 g) was submitted to silica gel (350 g) and eluted with $\mathrm{CHCl}_{3}-\mathrm{Me}_{2} \mathrm{CO}(8: 1,4: 1,2: 1)$, to give subfractions E-F. Subfraction E was purified by recrystallization from cold $\mathrm{MeOH}$ to give compound $\mathbf{1}$ (485.6 mg) and compound $2(18 \mathrm{mg})$. Subfraction $\mathrm{F}$ was first separated on $\mathrm{RP}-18$ using $\mathrm{MeOH}-\mathrm{H}_{2} \mathrm{O}$ and then on Sephadex LH-20 $\left(\mathrm{MeOH}-\mathrm{H}_{2} \mathrm{O}=9: 1\right)$, to give compounds $8(162.7 \mathrm{mg})$ and 9 (58.3 mg).

Microdon A (1): colorless square crystals $(\mathrm{MeOH})$. M. p. $174-176^{\circ} \mathrm{C} .-\mathrm{UV}\left(\mathrm{CHCl}_{3}\right): \lambda_{\max }=243 \mathrm{~nm} .-[\alpha]_{\mathrm{D}}^{20}=$ $+36.8\left(c=0.38, \mathrm{CHCl}_{3}\right)$. - IR $(\mathrm{KBr}): v=1723,1652$ $(\mathrm{C}=\mathrm{O}) \mathrm{cm}^{-1}$. $-\mathrm{MS}((+)-\mathrm{ESI}): \mathrm{m} / z=329[\mathrm{M}+\mathrm{H}]^{+} .-\mathrm{HRMS}$ ((+)-ESI): $m / z=329.1774$ (calcd. 329.1752 for $\mathrm{C}_{20} \mathrm{H}_{25} \mathrm{O}_{4}$, $\left.[\mathrm{M}+\mathrm{H}]^{+}\right) .-{ }^{1} \mathrm{H}$ NMR $\left(500 \mathrm{MHz}, \mathrm{CDCl}_{3}\right)$, and ${ }^{13} \mathrm{C} \mathrm{NMR}$ $\left(100 \mathrm{MHz}, \mathrm{CDCl}_{3}\right)$ spectral data see Table 1.

Microdon B (2): colorless square crystals $(\mathrm{MeOH})$. M.p. $192-193.5{ }^{\circ} \mathrm{C}$. $-\mathrm{UV}\left(\mathrm{CHCl}_{3}\right): \lambda_{\max }=243 \mathrm{~nm}$. $[\alpha]_{\mathrm{D}}^{20}=-28.7\left(c=0.36, \mathrm{CHCl}_{3}\right) .-\mathrm{IR}(\mathrm{KBr}): v=3323$ (OH), 1740, $1653(\mathrm{C}=\mathrm{O}) \mathrm{cm}^{-1}$. - MS ((+)-ESI): $\mathrm{m} / \mathrm{z}=$ $361[\mathrm{M}+\mathrm{H}]^{+} .-\mathrm{HRMS}((+)-\mathrm{ESI}): \mathrm{m} / z=361.1666$ (calcd. 361.1651 for $\left.\left.\mathrm{C}_{20} \mathrm{H}_{25} \mathrm{O}_{6},[\mathrm{M}+\mathrm{H}]\right]^{+}\right)$. $-{ }^{1} \mathrm{H}$ NMR $(500 \mathrm{MHz}$, $\left.\mathrm{CDCl}_{3}\right)$, and ${ }^{13} \mathrm{C}$ NMR $\left(100 \mathrm{MHz}, \mathrm{CDCl}_{3}\right)$ spectral data see Table 1.

\section{Acknowledgements}

The authors are grateful to the National Natural Science Foundation of China (C30670214), National Basic Resarch Program of China (973 Program 2009CB522300) and the Chinese Academy of Science (KSCX2-YW-N-014, XiBuZhiGuang Project) for financial support and to the members of the analytical group in the State Key Laboratory of Phytochemistry and Plant Resources in West China, Kunming Institute of Botany, Chinese Academy of Sciences, for the spectral measurements.
[1] Kunming Institute of Botany, Jiangsu Institute of Botany, ZhonghuaBencao Gangyao daiyaojuan, Shanghai Science and Technology Press, Shanghai, 2005, pp. 52.

[2] Yunnan Institute of Tropical Botany, Chinese Academy of Science, Xishuangbanna Daiyaozhi, Xishuangbanna Health Bureau Press, Xishuangbanna, 1979, pp. 15.
[3] W. Qiong, S. D. Luo, J. Peng, Y. F. Wang, Helv. Chim. Acta 2007, 90, $1360-1365$.

[4] R. A. Goodman, E. Oldfield, A. Allerhand, J. Amer. Chem. Soc. 1973, 95, 7553-7558.

[5] R. T. Aplin,T. G. Halsall, T. Norin, J. Chem. Soc. 1963, 6, 3269-3273.

[6] R. E. Gorbett, S. Coming, J. Chem., Soc. Perkin 1972, $2827-2829$. 
[7] H. Wagner, V. M. Chari, Tetrahedron Lett. 1976, 21, $1799-1802$.

[8] M. Andrew, S. Madhavlal, J. Indian Chem. Soc. 1931, 8, 575-580.

[9] S. K. Sharma, M. Ali, J. Indian Chem. Soc. 1995, 72, $339-342$.

[10] C. C. Shen, Y.S. Chang, L. K. Ho, Phytochemistry 1993, 34, $843-845$.

[11] P. Puebla, J.L. Lopez, M. Guerrero, R. Carron, M. L.
Martin, L. S. Roman, A.S. Feliciano, Phytochemistry 2003, 62, 551-555.

[12] R. Maurya, V. Wazir, A.Tyagi, R. S. Kapil, Phytochemistry 1995, 3, 659-661.

[13] S. R. Wilson, L. A. Neubert, J.C. Huffman, J. Amer. Soc. 1976, 9, 3669-3674.

[14] W. Tang, H. Hioki, K. Harada, M. Kubo, Y. Fukuyama, J. Nat. Prod. 2008, 71, $1760-1763$. 